\title{
Subclinical hypothyroidism and risk to carotid atherosclerosis
}

\author{
Hipotireoidismo subclínico e risco de aterosclerose carotídea
}

Velkoska Nakova Valentina', Bosevski Marijan², Dimitrovski Chedo ${ }^{3}$, Krstevska Branka ${ }^{3}$

\begin{abstract}
Objective: The aim of this study was to assess whether subclinical hypothyroidism (SCH) is associated with carotid atherosclerosis, as well as dyslipidemia, and arterial hypertension. Subjects and methods: The study included 69 consecutive patients with newly diagnosed $\mathrm{SCH}$, and 30 matched healthy controls. Body mass index (BMI), TSH, fT4, antibodies to thyroid peroxidase (TPOabs), lipids, blood pressure, mean and maximum carotid intima-media thickness (CIMT) were determined in all participants. Results: Mean values of CIMT, triglycerides, and total cholesterol/HDL-C ratio were significantly different in $\mathrm{SCH}$ patients versus matched controls. Linear multiple regression analysis demonstrated that $\mathrm{TSH}$, diastolic blood pressure and triglycerides were independent predictors of mean CIMT, fT4 for maximum CIMT; and that $\mathrm{TSH}, \mathrm{fT} 4$, age, and total cholesterol/HDL-C ratio were independent predictors of the presence of carotid plaques. Conclusion: Our data revealed that $\mathrm{SCH}$ is associated with increase in CIMT and presence of carotid plaques, independent of classical risk factors for atherosclerosis. Arq Bras Endocrinol Metab. 2011;55(7):475-80
\end{abstract}

Keywords

Subclinical hypothyroidism; atherosclerosis; dyslipidemia; arterial hypertension; carotid intima-media thickness

\section{RESUMO}

Objetivo: O objetivo deste estudo foi avaliar se o hipotireoidismo subclínico (HSC) está associado a aterosclerose de carótida, dislipidemia e hipertensão arterial. Sujeitos e métodos: $\mathrm{O}$ estudo incluiu 69 pacientes consecutivos recém-diagnosticados com HSC e 30 controles pareados. Índice de massa corpórea, TSH, T4L, anticorpos antiperoxidase (TPO), perfil lipídico, pressão arterial, espessamento carotídeo íntima-média máximo (ECIM) e médio foi determinado em todos os indivíduos. Resultados: Os valores médios de ECIM, triglicérides e razão colesterol total/C-HDL foram significantemente diferentes entre pacientes e controles. Regressão linear múltipla demonstrou que TSH, pressão arterial diastólica e triglicérides foram fatores independentes preditores de ECIM médio, T4L para ECIM máximo eTSH,T4L, idade e colesterol total/HDL-C para presença de placa carotídea. Conclusão: Nossos resultados indicam que HSC é associado com aumento do ECIM e presença de placas carotídeas, independentemente dos fatores de risco clássicos para aterosclerose. Arq Bras Endocrinol Metab. 2011;55(7):475-80

\section{Descritores}

Hipotireoidismo subclínico; aterosclerose; dislipidemia; hipertensão arterial; espessamento carotídeo íntima-média máximo

\section{INTRODUCTION}

Gubclinical hypothyroidism $(\mathrm{SCH})$ is a common condi$\checkmark$ tion affecting $4 \%-20 \%$ of the general population. SCH is defined as increased serum thyrotropin (TSH) concentrations and normal serum free thyroxine levels (fT4) (1).

Patients with primary hypothyroidism are at a three times greater risk for early atherosclerosis, as
1 School of Medical Sciences, Goce Delcev University, Stip, R. Macedonia ${ }^{2}$ Cardiovascular Disease Clinic, Medical School, Skopje, R. Macedonia ${ }^{3}$ Endocrinology Diabetes and Metabolic Disorders Clinic Medical School, Skopje, R. Macedonia

Correspondence to: Velkoska Nakova Valentina School of Medical Sciences, University "Goce Delcev" Krste Misirkov BB 2000 Stip, R. Macedonia valentina.velkoska@yahoo.com valentina.velkovska@ugd.edu.mk

Received on 19/July/2011 Accepted on $10 / 0 c t / 2011$ shown independently for other risk factors, such as atherogenic lipid profile, hypertension and impaired endothelial function. Whether SCH has influence on the same risk factors and is associated with atherosclerosis is still under debate (2). Some studies showed that there is an association (3-5), but others did not $(6,7)$. 
Because of these controversies, the benefit from thyroid replacement therapy in $\mathrm{SCH}$ is unclear.

The carotid intima-media thickness (CIMT) is used as a parameter for determining current subclinical atherosclerotic changes. Carotid plaques have been shown to be independent predictors of future vascular events $(8,9)$. If $\mathrm{SCH}$ is associated with greater CIMT and carotid plaques, thyroid hormone replacement therapy is required.

The aim of this study was to assess whether $\mathrm{SCH}$ is associated with carotid atherosclerosis, as measured by the increase in CIMT and presence of plaques.

\section{MATERIALS AND METHODS}

\section{Patients}

At the Department of Endocrinology Diabetes and Metabolic Disorders, Skopje, R. Macedonia, 69 consecutive patients with newly diagnosed $\mathrm{SCH}$ were examined. The criteria for SCH were: normal fT4 (10.3$24.45 \mathrm{pmol} / \mathrm{L})$ and elevated TSH $(4.2<\mathrm{TSH}<20.0$ $\mathrm{mU} / \mathrm{L})$ serum levels in at least two thyroid function tests measured no less than two weeks apart (10). Thirty healthy, euthyroid subjects, defined as patients with reference values of fT4 and TSH (0.2-4.2 mU/L), were included in the study as a control group. None of the patients had a previous history of thyroid disease, arterial hypertension, or took any medication for thyroid disease, arterial blood pressure or lipid metabolism. Patients with diabetes mellitus, liver or renal disease, chronic pancreatitis, primary hyperlipidemia, ovulatory dysfunction, pregnancy and infertility were excluded from the study.

Body mass index (BMI), TSH, fT4, TPOabs, total lipids, total cholesterol, high-density lipoprotein cholesterol (HDL-C), low-density lipoprotein cholesterol (LDL-C), triglycerides, blood pressure, mean and maximum carotid intima-media thickness (CIMT and max CIMT) were determined in all participants.

\section{METHODS}

\section{Laboratory analysis}

Blood samples were drawn at 8 am, after a 14-hour fast. Blood samples for lipoproteins were analyzed using Cobas Integra 700, according to standard methods. Total cholesterol and triglycerides were determined by full enzymatic methods (TH-CHOD-POD-PAP and
triglycerides-GPO; Cobas Integra 700, Hoffmann-La Roche, Basel, Switzerland). HDL-C was measured by the polyanion precipitation method, while LDL-C was calculated using the Friedewald formula. LDL-C were fractioned using ultracentrifugation in cases, when triglycerides exceeded $4 \mathrm{mmol} / \mathrm{L}$. Serum TSH and free T4 concentrations were measured using an Immulite 2000 chemiluminescent analyzer (Siemens Medical Solutions Diagnostics, Los Angeles, CA, USA). The sensitivity of the assays was $0.004 \mu \mathrm{U} / \mathrm{mL}$ and $0.3 \mathrm{ng} /$ $\mathrm{dL}$, respectively. TPOabs was determined by the immunometric assay from Diagnostic Products Corporation (Los Angeles, CA). For positive TPOabs, values over $34 \mathrm{IU} / \mathrm{mL}$ were obtained.

\section{Measurement of blood pressure, height, and body weight}

Blood pressure was measured twice on the right hand, with a desk-model sphygmomanometer after five minutes at rest in a sitting position. There was a $3-\mathrm{min}$ interval between the two measurements for each patient, and the mean value of the two measurements was used. In the case of hypertension $(\geq 140 / 90 \mathrm{mmHg})$, the measurement was repeated after 5 minutes.

Patients were weighed without clothes and shoes on an electronic scale, in the morning fasting. Their height was measured to the nearest $\mathrm{cm}$ with a stadiometer. Body mass index (BMI) was calculated as body weight (in $\mathrm{kg}$ ) divided by the square of body height (in meters).

\section{Carotid ultrasound}

The risk for atherosclerosis was estimated by the ultrasound system HP Agilent S4500. To avoid variations, the examination was performed by the same experienced physician, who was blind to the patients' risk factors. Mean and maximum CIMT were determined by B-mode ultrasound using a linear transducer (7.5-10 MHz). These values were calculated as a mean value of two measurements on a segment free of plaque in the right common carotid artery. Plaque was defined as a localized thickened lesion $(\geq 1.1 \mathrm{~mm})$. The study protocol was based on the Mannheim consensus (11). Intra-observer variability was up to $6 \%$, as previously published.

\section{Ethical aspects}

All patients gave informed consent to participate in the study, after the research protocol was explained to 
them. The study was carried out according to the Declaration of Helsinki.

\section{Statistical analysis}

Statistical analyses were performed by SPSS 11.0. The $\mathrm{t}$-test was used for the analysis of quantitative variables. $\chi^{2}$-test was used for the analysis of qualitative variables. Multivariate analysis was done by putting BMI, TSH, fT4, TPOabs, systolic and diastolic blood pressure, total lipids, triglycerides, total cholesterol, HDL-C, LDL-C, total cholesterol/HDL$-\mathrm{C}, \mathrm{LDL}-\mathrm{C} / \mathrm{HDL}-\mathrm{C}$, and age in the model.

\section{RESULTS}

In this study, 99 patients were analyzed. They were 42.8 \pm 15.2 years old, and 10 were men and 89 women. There were not any differences in age, gender, BMI, number of women in menopause, and smoking habits between the SCH and control group (Table 1, NS in all cases).

Table 1. Personal and hormonal characteristics of the SCH and control group

\begin{tabular}{lccc}
\hline & $\begin{array}{c}\text { SCH group } \\
\mathbf{n = 6 7}\end{array}$ & $\begin{array}{c}\text { control group } \\
\mathbf{n = 3 0}\end{array}$ & P value \\
\hline Sex (m : f) & $7: 62(10.1 \%)$ & $3: 27(10 \%)$ & $\mathrm{NS}$ \\
Age (years) & $42.4 \pm 16.2$ & $43.6 \pm 12.8$ & $\mathrm{NS}$ \\
BMl (kg/m²) & $27.8 \pm 5.6$ & $25.4 \pm 5.1$ & $\mathrm{NS}$ \\
Menopauses & $18(29 \%)$ & $8(29.6 \%)$ & $\mathrm{NS}$ \\
Smoking & $12(17.4 \%)$ & $5(16.6 \%)$ & $\mathrm{NS}$ \\
fT4 pmol/L & $\mathbf{1 4 . 5} \pm \mathbf{2 . 8}$ & $\mathbf{1 5 . 7} \pm \mathbf{2 . 5}$ & $\mathbf{p}=\mathbf{0 . 0 4}$ \\
TSH $\mathbf{~ m U / L}$ & $\mathbf{7 . 9} \pm \mathbf{3 . 6}$ & $\mathbf{1 . 5} \pm \mathbf{0 . 8}$ & $\mathbf{p}<\mathbf{0 . 0 0 0 0 0 1}$ \\
anti-TPO & $\mathbf{4 1 / 6 0 ( 6 8 . 3 \% )}$ & $\mathbf{3 / 2 4} \mathbf{( 1 2 . 5 \% )}$ & $\mathbf{p}<\mathbf{0 . 0 0 0 1 *}$ \\
\hline
\end{tabular}

Results are presented as means \pm std deviation and percentages. NS: no significance. ${ }^{*}$ Chisquare test, Yates correction factor.

Free thyroxine was significantly lower in the $\mathrm{SCH}$ group. Prevalence of positive TPOabs was significantly higher in the SCH group $(68.3 \%$ vs. $12.5 \%, \mathrm{p}<0.0001)$.

\section{Differences in lipid status and blood pressure between SCH and control group}

Patients with SCH had significantly higher mean triglycerides, and total cholesterol/HDL-C ratio. Serum concentration of total lipids, total cholesterol, HDL-C, LDL-C, and LDL-C/HDL-C ratio were not statistically significant. Mean systolic and diastolic blood pressure were higher in the SCH group, but the differences were not statistically significant (Table 2 ).
Table 2. Differences in the variables analyzed in the SCH and control group

\begin{tabular}{lccc}
\hline Variables & $\begin{array}{c}\text { SCH group } \\
\mathbf{n = 6 7}\end{array}$ & $\begin{array}{c}\text { control group } \\
\mathbf{n = 3 0}\end{array}$ & $\begin{array}{c}\text { t-test } \\
\mathbf{p} \text { value }\end{array}$ \\
\hline Total lipids (mmol/L) & $8.71 \pm 1.9$ & $8.14 \pm 1.5$ & 0.19 \\
Triglycerides (mmol/L) & $\mathbf{1 . 7 0} \pm \mathbf{1 . 1}$ & $\mathbf{1 . 1 8} \pm \mathbf{0 . 6}$ & $\mathbf{0 . 0 1 6}$ \\
Total cholesterol (mmol/L) & $5.46 \pm 1.3$ & $5.20 \pm 0.9$ & 0.34 \\
HDL-C (mmol/L) & $1.33 \pm 0.37$ & $1.46 \pm 0.38$ & 0.12 \\
LDL-C (mmol/L) & $3.42 \pm 1.09$ & $3.33 \pm 0.79$ & 0.67 \\
Total chol/HDL-C (mmol/L) & $\mathbf{4 . 4 4} \pm \mathbf{1 . 6 0}$ & $\mathbf{3 . 7 6} \pm \mathbf{1 . 0 3}$ & $\mathbf{0 . 0 3 7}$ \\
LDL-C/HDL-C (mmol/L) & $2.78 \pm 1.22$ & $2.44 \pm 0.87$ & 0.17 \\
Systolic pressure (mmHg) & $128 \pm 20.7$ & $121.8 \pm 16.5$ & 0.11 \\
Diastolic pressure (mmHg) & $81.66 \pm 12.3$ & $78.6 \pm 9.1$ & 0.19 \\
CIMT (mm) & $\mathbf{0 . 6 1} \pm \mathbf{0 . 1}$ & $\mathbf{0 . 5 6} \pm \mathbf{0 . 1}$ & $\mathbf{0 . 0 3 4}$ \\
max CIMT (mm) & $0.65 \pm 0.1$ & $0.64 \pm 0.1$ & 0.65 \\
\hline
\end{tabular}

Results are presented as means \pm standard deviation.

\section{Differences in carotid intima-media thickness between SCH and control group}

Patients with SCH had statistically significantly greater mean CIMT then the control group (Table 2, Figure 1). But maximum CIMT values between the groups were not statistically significant (Table 2 ). When we compared the mean and maximum values of CIMT for men and women in the SCH group, we did not find statistically significant differences (Figure 2).

\section{Impact of TPOabs on risk factors for atherosclerosis}

There was no statistically significant difference in mean values of lipids and blood pressure according to the presence of TPOabs in the SCH group. Those who had positive TPOabs had greater CIMT $(0.61 \pm 0.1 \mathrm{~mm}$, vs. $0.56 \pm 0.09 \mathrm{~mm}, \mathrm{p}=0.08)$, but the difference was not statistically significant.

\section{Carotid atherosclerosis in SCH and control group}

Carotid atherosclerosis was determined in both groups. Seven patients from SCH group and one from the control group had carotid plaques. Thus, $\mathrm{SCH}$ group had a greater prevalence of carotid plaques compared with the control group ( $10.1 \%$ vs. $3.3 \%)$. When age was considered, all patients from both groups with carotid plaques were women.

Multiple linear regression was used to determine the impact of risk factors as independent predictors on the dependent variables mean CIMT, max CIMT, and carotid plaques. TSH, triglycerides and diastolic blood pressure were independent predictors of mean CIMT. While fT4 was an independent predictor of max CIMT. TSH, fT4, age, and ratio of total cholesterol/HDL-C were independent predictors of the presence of carotid plaques (Table 3 ). 


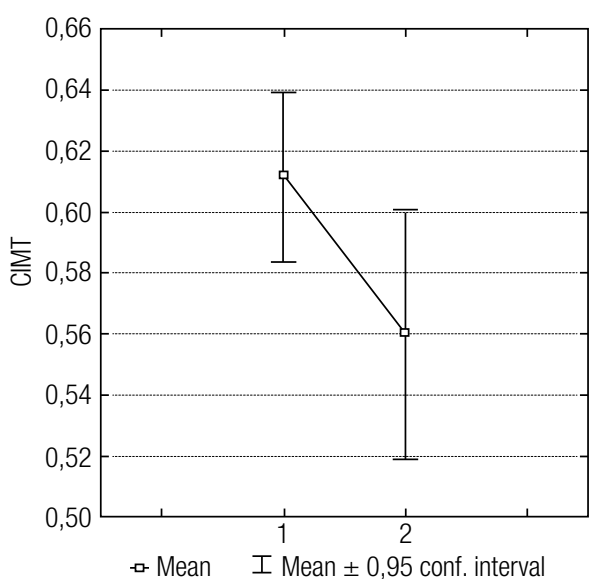

1: $\mathrm{SCH}$ group, 2: control group

Figure 1. Mean CIMT values in SCH and control group.

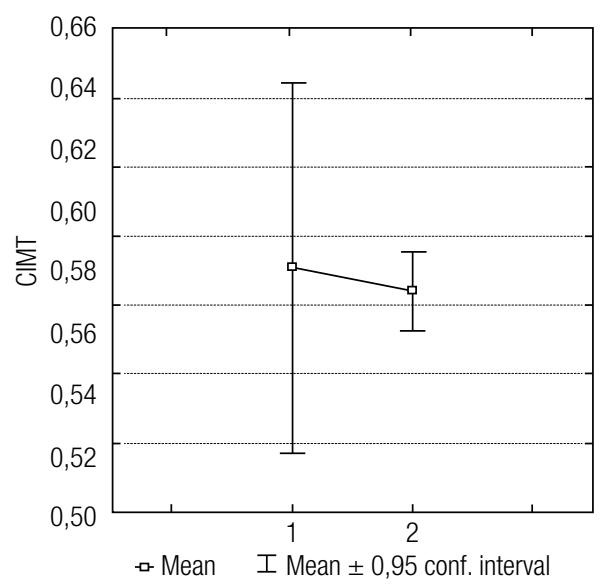

1: men; 2: women.

Figure 2. Mean CIMT values in men and women from SCH group.

Table 3. Influence of risk factors in mean and maximum CIMT, and presence of plaques

\begin{tabular}{lccccc}
\hline & \multicolumn{2}{c}{$\begin{array}{c}\text { Unstandardized } \\
\text { Coefficients }\end{array}$} & $\begin{array}{c}\text { Standardized } \\
\text { Coefficients }\end{array}$ & t & Sig. \\
\cline { 2 - 4 } & B & Std. Error & Beta & & \\
\hline CIMT & & & & & \\
(Constant) & .259 & .106 & & 2.441 & .021 \\
TSH & .009 & .004 & .313 & 2.339 & .026 \\
Diastolic & .004 & .001 & .537 & 2.871 & .008 \\
Triglycerides & .059 & .025 & .434 & 2.310 & .028 \\
max CIMT & & & & & \\
(Constant) & .757 & .267 & & 2.841 & .008 \\
fT4 & -.014 & .006 & -.391 & -2.261 & .032 \\
Plaques & & & & & \\
(Constant) & 0.172 & 0.722 & & 0.238 & 0.814 \\
TSH & 0.040 & 0.019 & 0.398 & 2.121 & 0.043 \\
fT4 & 0.049 & 0.023 & 0.435 & 2.165 & 0.039 \\
Age & 0.012 & 0.004 & 0.567 & 2.718 & 0.011 \\
Total hol/HDLC & 0.116 & 0.051 & 0.522 & 2.258 & 0.032 \\
\hline
\end{tabular}

The table shows only variables with predictive values.
In healthy patients, only age was an independent predictor of CIMT.

\section{DISCUSSION}

The results show that patients with $\mathrm{SCH}$ differ from healthy euthyroid individuals matched by sex, age, and $\mathrm{BMI}$ in the mean values of triglycerides, atherogenic ratio of total cholesterol/HDL-C, and mean CIMT.

Several studies have shown an association between SCH and hypercholesterolemia $(1,12)$, but other studies have not (13-16). Even though TSH is suggested as a major factor in the relationship between dyslipidemia and $\mathrm{SCH}$, the present study did not confirm this finding. The reasons for the differences between these studies are not clear. Maybe the weak relationship between TSH and total cholesterol is responsible for these differences. The $1 \mathrm{mU} / \mathrm{L}$ increase in TSH resulted in a $0.02 \mathrm{mmol} / \mathrm{L}$ increase in total cholesterol (12). The present study may require a larger group of patients to show statistical significance.

Monzani and cols. (17) and Nagasaki and cols. (18) showed increased CIMT in patients with $\mathrm{SCH}$. Kim and cols. (19) showed a difference in total cholesterol, LDL-C, and mean CIMT $(0.66 \pm 0.1 \mathrm{~mm}$, vs. $0.57 \pm 0.08 \mathrm{~mm}$ ) in $\mathrm{SCH}$, compared with healthy control groups. In the present study, CIMT differed significantly $(0.61 \pm 0.1 \mathrm{~mm}$, vs. $0.56 \pm 0.09 \mathrm{~mm})$, although the difference was not as great as in the study by Kim and cols. (19). The difference of CIMT in the study of Kim and cols. (19) is perhaps due to differences in mean cholesterol between the groups. In the present study, there was no difference in mean total cholesterol, and SCH had a direct impact on CIMT, regardless of lipid status. But we should not ignore the fact that both groups differed in mean triglycerides and total cholesterol/HDL-C ratio.

Plaque formation is an advanced stage of atherosclerosis. Great prevalence of carotid plaques in the group with subclinical hypothyroidism shown in the present paper suggests that these patients have an increased risk of cardiovascular disease compared with healthy patients. Sex-specific differences in CIMT values and plaque prevalence were previously demonstrated. Men have greater CIMT and worse plaque profile (20). But in the present study, there was no difference in mean and maximum CIMT between men and women. The 
prevalence of carotid plaques was higher in women than men. That is due to the lower number of men compared with women in the study, which is logical for thyroid diseases.

Multiple linear regression analysis showed that $\mathrm{TSH}$, triglycerides, and diastolic blood pressure are independent predictors of mean CIMT, while fT4 proved to be an independent predictor of max CIMT, which is similar to previous findings (21). As fT4 was significantly lower in the SCH group and negatively correlated with mean CIMT, and showed to be an independent predictor of max CIMT, lower fT4 is a risk factor for atherosclerosis, even when in reference range. This suggests that $\mathrm{SCH}$ is associated with increase in CIMT, independent of the influence of classical risk factors (age, hypertension, dyslipidemia), which was also shown in table 3 . Even more $\mathrm{TSH}$ and fT4 were independent predictors for carotid plaques. Other studies confirmed that TSH in $\mathrm{SCH}$ patients is related with carotid atherosclerosis (22), and low fT4 may adversely affect cardiovascular risk due to its effect on CIMT (23).

Different mechanisms are involved in atherosclerosis caused by $\mathrm{SCH}$. Thyroid autoimmunity is one of these mechanisms. Hashimoto thyroiditis is the most common condition causing SCH. Recently, it has been shown that Hashimoto thyroiditis is responsible for chronic inflammation, which causes endothelial dysfunction, a promoter of atherosclerosis. Abnormal immune response mediated by immune complex causes vascular damage (24). However, this mechanism is not sufficiently clear. We did not measure markers of inflammation or oxidative stress to show that inflammation is responsible for the association between SCH and CIMT, nor for the etio$\operatorname{logy}$ of SCH. So it cannot be said that Hashimoto thyroiditis is the cause of SCH. But the presence of TPOabs was recorded. In the Rotterdam study (5) the incidence of atherosclerosis was higher in $\mathrm{SCH}$ in the presence of positive TPOabs. In this study, patients with positive TPOabs had greater CIMT $(0.61 \pm 0.1 \mathrm{~mm}, v s .0 .56 \pm 0.09 \mathrm{~mm}, \mathrm{p}=0.08)$, but this finding was not statistically significant. As the analysis included a total of 55 persons, i.e., 17 with negative and 38 positive TPOabs, and $\mathrm{p}$ was close to statistical significance, we cannot confirm with certainty that the autoimmune etiology of $\mathrm{SCH}$ was not responsible for greater CIMT. Linear regression analysis did not show that positive TPOabs were in- dependent predictors of CIMT and carotid plaques. However, the mechanism has yet to be clarified.

Besides TSH, triglycerides were also independent risk factors for mean CIMT. This study showed that patients with $\mathrm{SCH}$ have significantly higher concentrations of triglycerides. A meta-analysis (25) revealed that an increase in triglycerides of only $1 \mathrm{mmol} / \mathrm{l}$ increases the risk of cardiovascular disease by $76 \%$. It is estimated that the values of triglycerides above $2.28 \mathrm{mmol} / \mathrm{l}$ and the ratio of total cholesterol/ HDL over 5 , contribute with $25 \%$ of all cardiovascular events. Thus, despite TSH, serum concentrations of triglycerides in $\mathrm{SCH}$ were responsible for the finding of greater CIMT. Also, total cholesterol/HDL-C ratio, whose mean value was significantly higher in the $\mathrm{SCH}$ group, showed to be an independent predictor of carotid plaques.

Hypertension is a major risk factor for carotid intima-media thickening. Meta-analysis of Wang and cols. (26) showed blood pressure values as independent factors for CIMT. Some studies $(27,28)$ found higher values of diastolic blood pressure in patients with $\mathrm{SCH}$. In the present study, diastolic blood pressure was an independent predictor of mean CIMT, but there was no difference between mean diastolic and systolic blood pressure in the studied groups. It is well known that aging increases blood pressure, as well as the incidence of SCH. The presence of both, diastolic hypertension and $\mathrm{SCH}$, will favor faster development of atherosclerosis.

The increased risk of atherosclerosis in patients with $\mathrm{SCH}$ is usually due to dyslipidemia and hypertension (5), but the results of this study, similar to other ones $(22,23,29)$, showed that $\mathrm{SCH}$ is associated with carotid atherosclerosis independent of these factors. Several studies $(17,18,30)$ showed a reduction in CIMT in patients with $\mathrm{SCH}$ after treatment with levothyroxine. The present study showed a clear association between SCH and CIMT, primarily because only young patients were included, who should in fact be a target group for atherosclerosis prevention. According to the results of the present study, to prevent or at least slow down the process of atherosclerosis in $\mathrm{SCH}$, patients with $\mathrm{SCH}$ should be on thyroid replacement therapy. However, prospective studies are needed to confirm this statement.

In conclusion, our data revealed that $\mathrm{SCH}$ is associated with increased CIMT and presence of carotid plaques, independent of classical risk factors for atherosclerosis. 
Disclosure: no potential conflict of interest relevant to this article was reported.

\section{REFERENCES}

1. Tunbridge WM, Evered DC, Hall R, Appleton D, Brewis M, Clark F, et al. Lipid profiles and cardiovascular disease in the Whickham area with particular reference to thyroid failure. Clin Endocrinol (Oxf). 1977;7:495-508.

2. Willeit J, Kiechl S, Oberhollenrer F, Rungger G, Egger G, Bonora $E$, et al. Distinct risk profiles of early and advanced atherosclerosis. Arterioscler, Tromb Vasc Biol. 2000;20:529-37.

3. Dean JW, Fowler PB. Exaggerated responsiveness to thyrotropin releasing hormone: a risk factor in women with coronary artery disease. BMJ. 1985;290:1555-61.

4. Squizzato A, Gerdes VEA, Brandjes DPM, Büller HR, Stam J. Thyroid diseases and cerebrovascular disease. Stroke. 2005;36:2302-10.

5. Hak AE, Pols HA, Visser T, Drexhage HA, Hofman A, Witteman JC. Subclinical hypothyroidism is an independent risk factor for atherosclerosis and myocardial infarction in elderly women: the Rotterdam study. Ann Intern Med. 2000;132:270-8.

6. Vanderpump MP, Tunbridge WM, French JM, Appleton D, Bates D, Clark F, et al. The development of ischemic heart disease in relation to autoimmune thyroid disease in a 20 -year follow-up study of an English community. Thyroid. 1996;6:155-60.

7. Rodondi N, Newman AB, Vittinghoff E, de Rekeneire N, Satterfield S, Harris TB, et al. Subclinical hypothyroidism and the risk of heart failure, other cardiovascular events, and death. Arch Intern Med. 2005;165:2460-6.

8. O'Leary DH, Polak JF. Intima-media thickness: a tool for atherosclerosis imaging and event prediction. Am J Cardiol. 2002;90(10C):18L-21L.

9. Bots ML, Hoes AW, Kondstaal PJ, Hofman A, Grobbee DE. Common carotid intima-media thickness and risk of stroke and myocardial infarction: the Rotterdam study. Circulation. 1997;96:1432-7.

10. Surks MI, Ortiz E, Daniels GH, Sawin CT, Col NF, Cobin RH, et al. Subclinical thyroid disease: scientific review and guidelines for diagnosis and management. JAMA. 2004;291:228-38.

11. Mannheim carotid intima-media thickness consensus (20042006). An update on behalf of the Advisory Board of the 3rd and 4th Watching the Risk Symposium, 13th and 15th European Stroke Conferences, Mannheim, Germany, 2004, and Brussels, Belgium, 2006.

12. Walsh JP, Bremner AP, Bulsara MK, O'leary P, Leedman PJ, Feddema $P$, et al. Thyroid dysfunction and serum lipids: a community-based study. Clin Endocrinol. 2005;63(3):670-5.

13. Parle JV, Franklin JA, Cross KW, Jones SR, Sheppard MC. Circulating lipids and minor abnormalities of thyroid function. Clin Endocrinol (Oxf). 1992;37:411-4.

14. Geul KW, van Sluisveld IL, Grobbee DE, Docter R, de Bruyn AM, Hooykaas $\mathrm{H}$, et al. The importance of thyroid microsomal antibodies in the development of elevated serum TSH in middle-aged women: association with serum lipids. Clin Endocrinol (Oxf). 1993;39:275-80.
15. Imaizumi M, Akahoshi M, Ichimaru S, Nakashima E, Hida A, Soda $M$, et al. Risk for ischemic heart disease and all-cause mortality in subclinical hypothyroidism. J Clin Endocrinol Metab. 2004;89:3365-70.

16. Hak AE, Pols HA, Visser T, Drexhage HA, Hofman A, Witteman JC. Subclinical hypothyroidism is an independent risk factor for atherosclerosis and myocardial infarction in elderly women: the Rotterdam study. Ann Intern Med. 2000;132:270-8.

17. Monzani F, Caraccio N, Korakowa M, Dardano A, Vittone F, Virdis $A$, et al. Effect of levothyroxine replacement on lipid profile and intima-media thickness in subclinical hypothyroidism: a double-blind, placebo-controlled study. J Clin Endocrinol Metabol. 2004;89:2099-106.

18. Nagasaki T, Inaba M, Yamada S, Shirakawa K, Nagata Y, Kumeda $Y$, et al. Decrease of brachial-ankle pulse wave velocity in female subclinical hypothyroid patients during normalization of thyroid function: a double-blind, placebo-controlled study. Eur J Endocrin. 2009;160:409-15.

19. Kim SK, Kim SH, Park KS, Park SW, Cho YW. Regression of the Increased Common Carotid Artery-intima Media Thickness in Subclinical Hypothyroidism after Thyroid Hormone Replacement. Endocr J. 2009;56:753-8.

20. Stensland-Bugge E, Bonaa KH, Joakimsen O, Njolstad I. Sex differences in the relationship of risk factors to subclinical carotid atherosclerosis measured 15 years later: the Tromso study. Stroke; 2000;31(3):574-81.

21. Takamura N, Akilzhanova A, Hayashida N, Kadota K, Yamasaki $H$, Usa T, et al. Thyroid function is associated with carotid intima-media thickness in euthyroid subjects. Atherosclerosis. 2009;204(2):e77-81.

22. Tian L, Gao C, Liu J, Zhang X. Increased carotid arterial stiffness in subclinical hypothyroidism. Eur J Intern Med. 2010;21(6):560-3.

23. Dullaart RP, de Vries R, Roozendaal C, Kobold AC, Sluiter WJ. Carotid artery intima media thickness is inversely related to serum free thyroxine in euthyroid subjects. Clin Endocrinol (Oxf). 2007;67(5):668-73.

24. Tièche M, Lupi GA, Gutzwiller F, Grob PJ, Studer H, Bürgi H. Borderline low thyroid function and thyroid autoimmunity. Risk factors for coronary heart disease? Br Heart J. 1981;46:202-6.

25. Austin MA. Epidemiology of hypertrigliceridaemia and cardiovascular disease. Am J Cardiol. 1999;83(9B):13F-6F.

26. Wang J, Staessen JA, Li Y, Van Bortel LM, Nawrot T, Fagard R, et al. Carotid intima-media thickness and antihypertensive treatment: a meta-analysis of randomized controlled trials. Stroke. 2006;37:1933-40.

27. Luboshitzky R, Aviv A, Herer P, Lavie L. Risk factors for cardiovascular disease in women with subclinical hypothyroidism. Thyroid. 2002;12:421-5.

28. Liu D, Jiang F, Shan Z, Wang B, Wang J, Lai Y, et al. A cross-sectional survey of relationship between serum TSH level and blood pressure. J Hum Hypertension. 2010;24(2):134-8.

29. Ciccone MM, De Pergola G, Porcelli MT, Scicchitano P, Caldarola $P$, lacoviello $M$, et al. Increased carotid IMT in overweight and obese women affected by Hashimoto's thyroiditis: an adiposity and autoimmune linkage? BMC Cardiovasc Disord. 2010;28:10-22.

30. Kebapcilar L, Comlekci A, Tuncel P, Solak A, Secil M, Gencel O, et al. Effect of levothyroxine replacement therapy on paraoxonase-1 and carotid intima-media thickness in subclinical hypothyroidism. Med Sci Monit. 2010;16(1):CR41-47. 